\title{
Exploring the Role of Quality of Work Life in Building Learning Organization: Applied Study on the Jordanian Pharmaceutical Manufacturing Companies
}

\author{
Yazan Emnawer Al Haraisa ${ }^{1}$ \\ ${ }^{1}$ Faculty of Business, Tafila Technical University, Jordan \\ Correspondence: Yazan Emnawer Al Haraisa, Faculty of Business, Tafila Technical University, AT-Tafila, P. O. \\ Box 179, Tafila, 66110, Jordan. E-mail: yazanhryza@yahoo.com
}

Received: May 22, 2018

doi:10.5539/ijbm.v13n9p24

\begin{abstract}
The pharmaceutical sector is one of the most important sectors at the level of countries because it has a big role in the development and sustain of other sectors. Therefore, the aim of this study examined the role of quality of work life in building learning organization in the (16) Jordanian Pharmaceutical manufacturing companies. For the sample unit and analysis involved the employees selected randomly from the different areas in the target companies. In addition to, the researcher designed a questionnaire containing of (31) items to get the data required from respondents in order to attain study objectives. Moreover, the current study sought to explore the role of quality of work life in building learning organization in the Jordanian Pharmaceutical Manufacturing companies. The result of the current study found that the quality of work life have a positive impact on building learning organization in Jordanian Pharmaceutical manufacturing companies and the highest impact for job satisfaction, then safety and healthy work conditions whereas the work environment is the lowest impact. Therefore, the current study recommends that the Jordanian Pharmaceutical manufacturing companies should focuses on quality of work life and their dimensions like job satisfaction, safety and healthy work conditions and work environment to build learning organization and achieve a benefits bundle or mutual interests to both employees and organizations. On the other hand, the current study applied on Jordanian Pharmaceutical Manufacturing companies'. Therefore, there is a need to conduct more study in the future because the result of current studies limited and narrow. And also there is a need to take other dimensions of quality of work life like adequate and fair compensation and the social relevance of work life. And conduct further future studies on other sectors such as hotel, hospital and tourism. Moreover, conducting comparative studies with others sectors such as banks and clothes manufacturing companies.
\end{abstract}

Keywords: quality of work life, learning organization, empowerment, continues learning, dialogue and inquiry, strategic leadership

\section{Introduction}

The pharmaceutical sector is one of the most important sectors at the level of countries because it has a big role in the development and sustain of other sectors. For this reason, there is an interested in researchers about pharmaceutical sector in Jordan, whereas these companies need to achieve quality through environment that characterized by safety and stability in order to enhance and increase their contributions in the society in the whole, this will help the organizations to work efficiently and effectively and then sustain their contribution in economic development.

The quality of work life is considered an necessary concept for the employees' life because this is refer to a suitable balance between work and personal life that will ensure in organizational productivity and job satisfaction of employee's (Islam, 2012). Therefore, the quality of work life is an important and critical factor that will help the organizations to keep and attract qualified personnel that will make them more interested in organization (Mbui, 2014).

Additionally, the learning organization is a critical factor that assists the organization to gain competitive advantage. According to (Wang \& Ellinger, 2008; Curado, 2006) described the learning organization as a main process helps the organization to achieve organizational success. 
According to Al-Abri and $\mathrm{Al}$-Hashmi (2007) the learning organization is a considered a philosophy requires many considerations should the organization take it in account such as a clear strategy and well defined goals.

Moreover, the learning organization is very important concept that used widely by academic and practitioners. Therefore, many researchers such as (Kanten, Kanten, \& Gurlek, 2015) suggested that the concept of learning organization emphasis on learning as a vital constituent such as (values, vision and goals).

One technique that uses to achieve the quality of work life was a learning organization approach through the learning organization components such as (empowerment, continues learning, dialogue and inquiry, strategic leadership). Therefore, the pharmaceutical sector striving achieve the quality of work life by adapting and using the learning organization components.

Therefore, the current study tries to explore the impact of quality of work life on learning organization. And through rereading the literature found there is an absence of studies that's linked and measured the impact of quality of work life on learning organization especially on the Jordanian Pharmaceutical Industries sector. For these reason, the study conducts in order to measure the impact of quality of work life on learning organization. On the other hand, most of the previous studies used the quality of work life and its impact on job involvement such as (Salem \& Abu Jara, 2015). Other previous studies focused on the Impact of quality of work life on employee satisfaction such as (Soni \& Rawal, 2014). Some of other previous studies focused on the Impact of quality of work life on job satisfaction such as (Bhatnagar \& Soni; Fatehi et al., 2015). Therefore, all of previous studies that mentioned which confirmed that quality of work life is very important element for the business organizations through encourage employees by providing a suitable work environment in order to attain the competitive advantage. However, the current study aims to augment and enrich the literature and fill or cover this gap in knowledge in this area by testing empirically the impact of the role of quality of work life in building learning organization'. Therefore, the main question of study is: what is the impact of quality of work life on building learning organization?

\section{Literature Review}

\subsection{Quality of Work Life}

Recently, the concept of quality of work life became a hot topic by researchers and at the same time there are many viewpoints about identified the comprehensive concept in order to cover all the elements and dimensions of quality of work life for several reasons: first, it will help the employees in organization to accomplish their tasks and functions accurately and timely in order to arrive the organization goals. Second, the quality of work life will achieve the welfare and happiness to employees in the organization. Therefore, the quality of work life subject is controversial among researchers. According to (Garg et al., 2012) they described the quality of work life as members in the organization are capable of satisfy their personal needs based on their experience. Other researchers such as (varghese \& Jayan, 2013) defined the quality of work life broadly as a part of whole quality of life which affected by working environment and not only relevant to job satisfaction.

Additionally, the quality of work life defined as a philosophy considered the individuals as assets (not added cost) which help the organization through their knowledge and skills and experience commitment to achieve their goals and objectives (Janmohammadi et al., 2015).

According to Mejbel et al. (2013) describes the quality of work life as a comprehensive program that designed in order to increase and achieve employees' satisfaction.

On the other side, the organization should have quality of work life to acquire new or potential employees and keep the current employees by finding suitable work environment for them. Therefore, the Nanjundeswaraswamy and swamy, (2012) mentioned that the high quality of work life is considered a fundamental requirement for organizations in order to progress and continue to attract new employees and maintain the current employees.

In general, the term of concept of quality of work life can be defined as positive emotional reactions and individuals attitudes about their job (Aketch et al., 2012). According to Anand (2014), the quality of work life involves eight dimensions like commitment to workplace, adequate and fair compensation, job satisfaction, skills utilization and opportunity for growth, training and development, safety and healthy working conditions, social integration in the work organization and work environment. According to Walton (1974) the dimensions of quality of work life involves adequate income and fair compensation, safe and healthy working conditions, immediate opportunity to use and develop human capacities, opportunity for continued growth and security, constitutionalism in the work organization, social integration in the work organization, work and the total life space and Social relevant of work life. 
Based on previous reviews the researcher selects the following variables (job satisfaction, safety and healthy working conditions, work environment) as dimensions of quality of work life for the purpose of current study.

\subsubsection{Job Satisfaction}

The job satisfaction is one of the most significant components or elements of quality of work life which indicate if the business organization successful or not. Hence, the successful of organizations should take in account workers morale and job satisfaction because this is very important in job performance (Muindi \& K'Obonyo, 2015). According to Islam (2012), the job satisfaction and external environment and personal effect are directly on quality of work life. Additionally, the linked between job satisfaction and quality of work life consider another part of working life which often examined by researchers (Sinha, 2012). Therefore, many researchers such as (Hassan et al., 2011) described the job satisfaction as favorableness or non-favorableness with which workers see their work.

According to Ganguly (2010), the job satisfaction is the attitudes of employees about their work or refers to a psychological behavior of employees to their works and also how the employees feel about their work.

From the above definitions we can reach to the following points:

1. Job satisfaction is one of the main pillars of business organizations to attain their goals.

2. Success in organizations depend on the range of satisfy the needs workers.

3. The job satisfactions describe the group of attitudes and values that employees hold toward their work.

4. It is impossible separated the concept of job satisfaction from quality of work life because the job satisfaction is a part of quality of work life.

\subsubsection{Safety and Healthy Work Conditions}

In recent years, there is much attention about Safety and healthy work conditions subject by academics and researchers. Therefore, the safety and healthy work conditions is considered a priority because it is very important and necessary in order to enhance and encourage the workers in the organization in many tools and methods (Muthuviknesh \& Kumar, 2014). Moreover, the organization should attract the employees to the health professions in order to reduce the risks and increase their performance .According to (Mathis \& Jackson, 2003) the Occupational safety and health refer to the general physical, mental and psychological welfare of the person. Moreover, the Safe and healthy working condition can be described as a safe physical working condition with minimum hours working (Walton, 1947).

Addition to, the Safe and healthy work conditions mean using suitable work procedures and tools which fit with the employees in the organization such as safe handling practices, first aid and avoid using dangerous materials and equipment and protective clothes and devices (Varghese \& Jayan, 2013).

On the other hand, some researchers such as (Kapinos et al., 2012, p. 7) divided the workplace conditions into three groups for major care providers such as physical environment, organizational culture and human resources practices.

The organizations whatever provide services or products should give more attention regarding a topic of safety and healthy work conditions by using protection tools to avoid the employees from injury and other dangerous cases. And the management of the organizations must take the procedures' and polices about health and safety their employee's in order to keep them more long time as possible.

\subsubsection{Work Environment}

The work environment plays a crucial role in providing quality of work life for staff or employees in the organization. Therefore, many organizations seek to make all the requirements of the work environment to be available such as the relationships between the supervisors and subordinates and between the coworkers due to the competition among business organizations and in order to enhance and achieve high performance. According Linguli (2013), the work environment is often described good or bad environment. The good environment achieved when the employees feel comfortable and appreciated in their position. Whereas, the bad work environment refers to the workers feel underappreciated and not satisfy or non-stability in their job.

\subsection{Learning Organization}

Nowadays, the term of learning organization has become used widely and commonly in many organizations. This is because majorities of organization have moved from traditional operations to complex and flexible one (Wang, 2006). According to Kanten, Kanten and Gurlek (2015), the Learning organization described as an organization that emphasis on learning as a critical element in many aspects such as its values, goals and visions 
as well as whole of its functions. Moreover, some researchers define the learning organization as an organization that encourages and promotes the learning to all their employees (members) and it converts permanently (Vemic, 2007).

According to Farrukh and Waheed (2015), the concept of learning organization is an organization that helps their employees to learning constantly and changes itself in order to achieve competitive advantage in the certain business environment.

The learning organization can be defined as a place or location where people learn together and improved team learning behavior in order to be effective organizational change agents (Aksu \& Ozdemir, 2005). According to Dawoood et al. (2015) described the learning organization as a group of people who have a constant and improved ability to learn inside the company. In the other words, the learning organization is focus on two sides which are the individuals or groups inside the organization and what they have of experiences and skills which reflect the willing and ability to learn, this will lead to achieve organization goals.

On the other hand, the learning organization needs a requirement like new vision of leadership which means the role of leadership by defining the vision and motivation in order to create or find mechanisms or tools to participate all of employees through share the vision and work together (Bordeianu et al., 2014).

Leufven et al. (2015) and Marsick and Watkins (2003) identified the seven dimensions of learning organization such as dialogue and inquiry, empowerment, continuous learning,, systems connections and embedded systems, team learning, collaboration and strategic leadership according to Leufven, Marsick and Watkins research, the current study adopted the following dimensions: empowerment, continues learning, dialogue and inquiry, and strategic leadership.

\subsubsection{Empowerment}

According to Goh (1998), the empowerment concept is important characteristic of learning organizations. In addition to, the concept of empowerment is considered an important feature of learning organization and can be defined as opinion which acts as an essential characteristic for organization in order to enhance and increase its learning ability (Farrukh \& Waheed, 2015, p. 78).

On the other hand, the empowerment is the tool that use organizations processes in order to find or generate and shared a combined vision and get the feedback or response from the organization members regarding the gap between the current position and the new vision (Marsick \& Watkins, 2003).

Therefore, the empowerment is the process that allowing or enabling members of organization to participate or share in policy making in order to aware how to get something done and evaluate their needs and find or create or find a collective vision ( Nazari \& Pihie, 2012).

\subsubsection{Continues Learning}

According to Nazari and Pihie (2012) the continues learning refer to how organization developing and improving the learning in organization by acquiring or learning values and skills and new knowledge, and then creating or find continuous learning opportunities through experiments in order to develop personal and job career.

Watkins and Marsick (2004) defined the Continues learning as an organization's effort to generate or create continuous learning opportunities for all of organization members. According to (Seng, 1990) continues learning help or assist the organization or individual to faster learn and perform or achieve the tasks distinctively from other competitors.

\subsubsection{Dialogue and Inquiry}

According to Nazari and Pihie (2012) defined the concept of dialogue and inquiry as the extent to which culture available in organization that allows to their members to have open connection with open mind talk, discuss and explain their skills and experiences. Moreover, other researcher defined the dialogue and inquiry as the existence of a learning culture that let the members in organization to communicate in an open fashion (Al-Qatamin \& Batayneh, 2015).

The dialogue and inquiry can be defined as philosophy that used by organization through focused on organization culture in order to enhance and encourage all the employees to deal with each other efficiently and effectively.

\subsubsection{Strategic Leadership}

According to Abuzaid (2016) Strategic leadership is described as a broader vision of leadership. Therefore, Strategic leadership refers to the leader role more than the personal ties linked the leader with it is whom follow 
the leader (Carter \& Greer, 2013; Lin \& McDonough, 2011; abuzaid, 2016). While (Montgomery, 2008) has been defined the strategic leadership as the leaders capability to inspire or generate and recreate causes for the organization's continued presence.

From the reviewing the studied related to strategic leadership; the strategic leadership can be defined as a philosophy or practices that used by a leader and the nature of relationship between the leader (supervisors) and the follower (subordinates) in order to achieve organization goals.

\section{Study Hypothesis}

The study basically aimed to explore the role of quality of work life in building learning organization.

Hence, the main hypothesis is:

H0: There is no statistically significant impact at significance level $(\alpha \leq 0.05)$ of quality of work life on learning organization. The main hypothesis is divided into several sub-hypotheses:

H01: There is no statistically significant impact at significance level $(\alpha \leq 0.05)$ of quality of work life on empowerment.

H02: There is no statistically significant impact at significance level $(\alpha \leq 0.05)$ of quality of work life on Continues learning.

H03: There is no statistically significant impact at significance level $(\alpha \leq 0.05)$ of quality of work life on dialogue and inquiry.

H04: There is no statistically significant impact at significance level $(\alpha \leq 0.05)$ of quality of work life on strategic leadership.

\section{Methodology}

The purpose of current study is the exploring the impact of quality of work life in building learning organization from the view of employees working in the Jordanian Pharmaceutical manufacturing companies. Therefore, the researcher in the current study adopted descriptive and analytical research methods to gather the data required from the respondents (targeted) by distributed the questionnaire and then analyze the collected data by used the statistical techniques.

\subsection{Study Population and Sample}

The population of study comprised of (16) Jordanians Pharmaceutical manufacturing companies. The study sample included all the study population. The sampling unit and analysis (respondents) included (200) employees selected randomly from the different areas in the target companies. Table (1) explains the characteristics of study sample (respondents') include the gender, years of experience in the company and their ages.

Table 1. Shows the characteristics of study sample

\begin{tabular}{llll}
\hline Variable & Category & Frequency & Percentage \\
\hline Gender & Male & 150 & $\mathbf{7 5 . 0 0}$ \\
& Female & 50 & $\mathbf{2 5 . 0 0}$ \\
Years of experience & Less than (5) years & 20 & $\mathbf{1 0 . 0 0}$ \\
& From (5) to less than (10) years & 32 & $\mathbf{1 6 . 0 0}$ \\
& From (10) to less than (15) years & 45 & $\mathbf{2 2 . 5 0}$ \\
& From (15) to less than (20) years & 57 & $\mathbf{2 8 . 5 0}$ \\
Age & (20) years and above & 46 & $\mathbf{2 3 . 0 0}$ \\
& From (18) to (25) years & 18 & $\mathbf{0 0 . 0 9}$ \\
& From (26) to (32) years & 42 & $\mathbf{2 1 . 0 0}$ \\
Total & From (33) to (40) years & 44 & $\mathbf{2 2 . 0 0}$ \\
& (41) years and above & 96 & $\mathbf{4 8 . 0 0}$ \\
\hline
\end{tabular}

\subsection{Study Instrument}

The study instrument composed a questionnaire developed according to the theoretical literature related to the quality of work life and learning organization. The questionnaire divided into three sections: The first section 
composed the general variables (personal information) of the respondents, like the gender, years of experience, and the age of respondents. The second section involves the paragraphs associated to the quality of work life variable included sub variables that measured by (5) items for job satisfaction, and (3) items for safety and healthy work conditions, and (5) items for work environment, which developed by the researcher based on (Anand, 2014; Walton, 1974) study. The third section of the questionnaire involves the paragraphs linked to the learning organization variable that measured by (3) items for empowerment, and (3) items for continues learning, and (3) items for dialogue and inquiry, and (3) items for strategic leadership adopted from (Leufven et al., 2015; Marsick \& Watkins, 2003). And the current study used the Likert Scale to answers the second and third part of questionnaire.

\subsection{Instrument Validity}

The instrument of study was presented to a group of academics and experts in the field of business administration in order to express their opinion regarding to procedures and the methodology of the current study and based on their opinions; the items of the questionnaire are comprehensives to all variables and the language is very simple. Therefore, the questionnaire is fit to the current research.

\subsection{Instrument's Reliability}

The current study used the Cronbach alpha coefficients in order to measure and confirm the consistency of internal among paragraphs of questionnaire. The value of Cronbach alpha for quality of work life items equal (0.79) while the value of Cronbach alpha for learning organization items equal (0.81) and the value for whole instrument equal $(0.783)$. Therefore, the values of Cronbach alpha are accepted because it is more than $(60 \%)$ according to (Sekaran, 2008).

\section{Discussion of results}

\subsection{Presentation of Data}

The table (2) and table (3) show the means and standard deviations for quality of work life and its dimensions (Independent Variable) and learning organization. Whereas the table (2) shows the means and standard deviations for quality of work life and its dimensions (Independent Variable).while table (3) shows the means and standard deviations for learning organization and its dimensions (dependent Variable).

Table 2. The table below shows the means and standard deviations for quality of work life and its dimensions (Independent Variable).

\begin{tabular}{lll}
\hline Job satisfaction & Means & Standard deviation \\
\hline 1. Organization recognizes and appreciates individual achievements. & 4.22 & 0.844 \\
2. I am satisfied with the freedom to make decisions at my level. & 3.62 & 0.995 \\
3. The Technology used in my job is the best in the Industry. & 4.05 & 0.839 \\
4. There is no discrimination of any type (social, racial, religious, sexual etc.). & 4.01 & 0.753 \\
5. Job requires my personal involvement. & 3.98 & 0.699 \\
Average & $\mathbf{3 . 9 7}$ & \\
Safety and healthy work conditions & Means & Standard deviation \\
6. Organization gives high priority for the safety of its workers. & 4.00 & 0.830 \\
7. My financial needs are fulfilled adequately by my pay. & 4.76 & 0.799 \\
8. Company provides good security equipment and health care measures. & 3.82 & 0.850 \\
Average & $\mathbf{4 . 1 9}$ & \\
Work environment & Means & Standard deviation \\
9. My seniors help me to do my job better. & 3.85 & 0.835 \\
10. For beginners this is a better place to start their career. & 3.76 & 0.866 \\
11. My views are taken into account in resolving work-related problems. & 3.82 & 0.952 \\
12. Workload given to me can be easily done. & 4.19 & 0.880 \\
13. The work load given is reasonable and attainable. & 3.96 & 0.932 \\
Average & $\mathbf{3 . 9 1}$ & \\
\hline
\end{tabular}

As explained in the above table 2 the results and finding refers that the safety and healthy work conditions levels for employees in the Jordanian pharmaceutical manufacturing companies are high with average of means (4.19). Also the item (My financial needs are fulfilled adequately by my pay) has the highest mean (4.76) while the item 
(Company provides good security equipment and health care measures) has the lowest mean (3.82) within safety and healthy work conditions. Moreover, the results explained that the item (Organization recognizes and appreciates individual achievements) has the highest mean (4.22) whereas the item (I am satisfied with the freedom to make decisions at my level) has the lowest mean (3.62) job satisfaction. And lastly the results from table 2 explained that the item (Workload given to me can be easily done) has the highest mean (4.19) while the item (For beginners this is a better place to start their career) has the lowest mean (3.76) within work environment.

Table 3. The table below shows the means and standard deviations for learning organization and its dimensions (dependent Variable)

\begin{tabular}{|c|c|c|}
\hline Empowerment & Means & $\begin{array}{l}\text { Standard } \\
\text { Deviations }\end{array}$ \\
\hline 14. My organization recognizes people for taking initiatives. & 3.93 & 0.869 \\
\hline $\begin{array}{l}\text { 15. My organization gives people control over the resources they need to accomplish their } \\
\text { work. }\end{array}$ & 3.72 & 0.958 \\
\hline 16. My organization supports employees who take calculated risks. & 4.20 & 0.740 \\
\hline Average & 3.95 & \\
\hline Continues learning & Means & Standard deviation \\
\hline 17. My organization, people help each other learn. & 3.00 & 0.870 \\
\hline 18. In my organization, people are given time to support learning. & 4.50 & 0.648 \\
\hline 19. In my organization, people are rewarded for learning & 3.80 & 0.890 \\
\hline Average & 3.76 & \\
\hline Dialogue and inquiry & Means & Standard deviation \\
\hline 26. In my organization, people give open and honest feedback to each other. & 4.00 & 0.698 \\
\hline 27. In my organization, whenever people state their view, they also ask what others think & 3.50 & 0.869 \\
\hline 28. In my organization, people spend time building trust with each other. & 4.10 & 0.748 \\
\hline Average & 3.86 & \\
\hline Strategic leadership & Means & Standard deviation \\
\hline 29. In my organization, leaders mentor and coach those they lead. & 3.46 & 1.048 \\
\hline 30. In my organization, leaders continually look for opportunities to learn. & 3.00 & 0.780 \\
\hline $\begin{array}{l}\text { 31. In my organization, leaders ensure that the organization's actions are consistent with its } \\
\text { values. }\end{array}$ & 3.65 & 0.660 \\
\hline Average & 3.37 & \\
\hline
\end{tabular}

As explained in the above table 3 the results and finding refers that the empowerment for employees in the Jordanian pharmaceutical manufacturing companies have a high level with average of means (3.95). In addition, the results from table 3 explained that the item (My organization supports employees who take calculated risks) has the highest mean (4.20) whereas the item (My organization gives people control over the resources they need to accomplish their work) has the lowest mean (3.72).

\subsection{Hypotheses Testing}

The current study used VIF test (Variance Inflation Factory), and test of Tolerance in order to confirm the suitability of data for the regression analysis test and confirm no correlation highly between the job satisfaction, safety and healthy work conditions and work environment (independent variables) (Multicollinearity) and Skewness Test in order to make sure there is a normal distribution of the data before using the regression analysis: The table 4 explains the results of both tests.

Table 4. Explains the values of variance inflation factory test, values of tolerance test, and values of Skewness test

\begin{tabular}{llll}
\hline $\begin{array}{l}\text { Independent Variables } \\
\text { (dimensions of quality of work life) }\end{array}$ & $\begin{array}{l}\text { Variance Inflation Factory } \\
\text { values }\end{array}$ & Tolerance values & $\begin{array}{l}\text { Skewness } \\
\text { values }\end{array}$ \\
\hline Job satisfaction & 2.59 & 0.471 & 0.597 \\
Safety and healthy work conditions & 2.99 & 0.459 & 0.581 \\
Work environment & 2.83 & 0.468 & 0.588 \\
\hline
\end{tabular}


As explained in the table above the results shown the Variance Inflation Factory values for whole independent variables lowest than (10) and Tolerance values highest than (0.05) that is refers to no correlation highly between the job satisfaction, safety and healthy work conditions and work environment (independent variables). In addition, the results from table 4 revealed that the values of Skewness lowest than (1) which indicates that there is a normal distribution of the data. Accordingly on these results the multiple linear regression analysis conducted in order to test the hypothesis of current study. The table 5 explains the model summary, and while the table 6 explains ANOVA analysis whereas a table (7,8, and 9) explains beta and t values for the hypothesis of research.

Table 5. The model summary

\begin{tabular}{lllll}
\hline Model & R & R Square & Adjusted R Square & Std. Error of The Estimate \\
\hline 1 & 0.882 & 0.774 & 0.763 & 0.408 \\
\hline
\end{tabular}

Note. *Predictors: (Constant), job satisfaction, safety and healthy work conditions, work environment.

The results of Table 5 indicate that the value of $\mathrm{R}$ square has reached (0.774) indicating that (\%77.4) of variance in variable (learning organization) can be explained by variation in quality of work life

Table 6. The results of ANOVA analysis

\begin{tabular}{llllll}
\hline Model & Sum of Squares & Df & Mean Square & F & Sig. \\
\hline 1 Regression & 300.192 & 4 & 61.522 & 1180.320 & 0.000 \\
Residual & 28.520 & 196 & 0.071 & & \\
Total & 328.712 & 200 & & & \\
\hline
\end{tabular}

Notes. *Predictors: job satisfaction, safety and healthy work conditions, work environment; **Dependent Variable: learning organization

The results of table 6 indicate that the value of $(\mathrm{F})$ is $(1180.320)$ and the significant $(0.000)$ this is less than the identified value (0.05) therefore; the model is appropriate or fit and acceptable.

Table 7. Presents the values of beta and $t$ for the main study hypothesis

\begin{tabular}{llllll}
\hline Dimensions of quality of work life & B & Std. Error & Beta & T & Sig. \\
\hline 1 (Constant) & 0.068 & 0.049 & & & \\
Job satisfaction & 0.751 & 0.035 & 0.650 & 33.221 & 0.000 \\
Safety and healthy work conditions & 0.700 & 0.029 & 0.689 & 29.949 & 0.000 \\
Work environment & 0.674 & 0.024 & 0.700 & 35.854 & 0.000 \\
\hline
\end{tabular}

Notes. * Statistically significant impact at significance level $(\alpha \leq 0.05) ; * *$ Dependent Variable: learning organization

As shown in the table above table 7, the results of multiple regression analysis indicate that the quality of work life affects learning organization. Also the beta and t-tests values shown that the job satisfaction, safety and healthy work conditions, and work environment as a dimensions of quality of work life has a positive impact on learning organization at $(\alpha \leq 0.05)$ and the highest impact for job satisfaction, and then for safety and healthy work conditions whereas the work environment is the lowest impact.

Table 8. Presents the values of beta and t for the first sub hypothesis

\begin{tabular}{llllll}
\hline Dimensions of quality of work life & B & Std. Error & Beta & T-test & Sig. \\
\hline 1 (Constant) & 0.074 & 0.060 & & & \\
Job satisfaction & 0.695 & 0.051 & 0.680 & 24.511 & 0.000 \\
Safety and healthy work conditions & 0.680 & 0.020 & 0.601 & 26.819 & 0.000 \\
Work environment & 0.490 & 0.030 & 0.620 & 20.604 & 0.000 \\
\hline
\end{tabular}

Notes. * Statistically significant impact at significance level $(\alpha \leq 0.05) ; * *$ Dependent Variable: Empowerment

The table 8 explained the multiple regression analysis results refers to the quality of work life affects the 
empowerment. Also, the beta and t-tests values shown that the dimensions of quality of work life (job satisfaction, safety and healthy work conditions, and work environment) have a positive impact on empowerment at $(\alpha \leq 0.05)$ and the job satisfaction get the highest impact, then safety and healthy work conditions whereas the work environment is the lowest impact.

Table 9. Presents the values of beta and $t$ for the second sub hypothesis

\begin{tabular}{llllll}
\hline Dimensions of quality of work life & B & Std. Error & Beta & T-test & Sig. \\
\hline 1 (Constant) & 0.075 & 0.061 & & & \\
Job satisfaction & 0.720 & 0.029 & 0.647 & 29.260 & 0.000 \\
Safety and healthy work conditions & 0.640 & 0.022 & 0.633 & 30.574 & 0.000 \\
Work environment & 0.510 & 0.028 & 0.661 & 20.604 & 0.000 \\
\hline
\end{tabular}

Notes. * Statistically significant impact at significance level $(\alpha \leq 0.05) ; * *$ Dependent Variable: continues learning

As shown in table 9 the results of multiple regression analysis indicate that the quality of work life affects the continues learning. Also the beta and t-tests values shown that the dimensions of quality of work life (job satisfaction, safety and healthy work conditions, and work environment) have a positive impact on continues learning at $(\alpha \leq 0.05)$ and the highest impact for job satisfaction, then safety and healthy work conditions whereas the work environment is the lowest impact.

Table 10. Presents the values of beta and $t$ for the third sub hypothesis

\begin{tabular}{llllll}
\hline Dimensions of quality of work life & B & Std. Error & Beta & T-test & Sig. \\
\hline 1 (Constant) & 0.073 & 0.060 & & & \\
Job satisfaction & 0.638 & 0.028 & 0.680 & 27.240 & 0.000 \\
Safety and healthy work conditions & 0.497 & 0.025 & 0.635 & 25.399 & 0.000 \\
Work environment & 0.557 & 0.023 & 0.652 & 29.110 & 0.000 \\
\hline
\end{tabular}

Notes. * Statistically significant impact at significance level $(\alpha \leq 0.05) ; *$ Dependent Variable: Dialogue and inquiry.

As shown in table (10) the results of multiple regression analysis indicate that the quality of work life affects the dialogue and inquiry. Also the beta and t-tests values shown that the dimensions of quality of work life (job satisfaction, safety and healthy work conditions, and work environment ) have a positive impact on dialogue and inquiry at $(\alpha \leq 0.05)$ and the highest impact for job satisfaction, then work environment whereas the safety and healthy work conditions is the lowest impact.

Table 11. Presents the values beta and t for the fourth sub hypothesis

\begin{tabular}{llllll}
\hline Dimensions of quality of work life & B & Std. Error & Beta & T-test & Sig. \\
\hline 1 (Constant) & 0.070 & 0.059 & & & \\
Job satisfaction & 0.721 & 0.028 & 0.680 & 28.390 & 0.000 \\
Safety and healthy work conditions & 0.567 & 0.022 & 0.636 & 29.476 & 0.000 \\
Work environment & 0.663 & 0.025 & 0.669 & 25.341 & 0.000 \\
\hline
\end{tabular}

Notes. * Statistically significant impact at significance level $(\alpha \leq 0.05) ; * *$ Dependent Variable: Strategic leadership

As shown in table 11 the results of multiple regression analysis indicate that the quality of work life affects the strategic leadership. Also the beta and t-tests values shown that the dimensions of quality of work life (job satisfaction, safety and healthy work conditions, and work environment ) have a positive impact on strategic leadership at $(\alpha \leq 0.05)$ and the highest impact for job satisfaction, then work environment whereas the safety and healthy work conditions is the lowest impact.

\section{Conclusion}

The current study sought to explore the role of quality of work life in building learning organization in the Jordanian pharmaceutical manufacturing companies. The results of the current study found that the quality of work life have a positive impact on building learning organization in Jordanian Pharmaceutical manufacturing companies and the highest impact for job satisfaction, then safety and healthy work conditions whereas the work 
environment is the lowest impact.

\section{Recommendations of Study}

Therefore, the present study recommends that the Jordanian Pharmaceutical manufacturing companies should focuses on quality of work life and their dimensions such as job satisfaction, safety and healthy work conditions and work environment to build learning organization and achieve a benefits bundle or mutual interests to both organizations and employees.

\section{Limitations of Study}

The present study applied on Jordanian pharmaceutical manufacturing companies. Therefore, the results of present study is limited and totally different from the sector to another section and from to country to another country. In the other words, the result of current studies limited and narrow and it is impossible to generalize it on other sectors.

\section{Further Researches}

According to limitations of present study there is a need to conduct more studies in the future. And there is a need to take other dimensions of quality of work life such as adequate and fair compensation and the social relevance of work life. And conduct further future studies in other sectors such as hotel, hospital and tourism. Moreover, conducting comparative studies with others sectors such as banks and clothes manufacturing companies.

\section{References}

Abuzaid, A. N. (2016). Testing the Impact of Strategic Leadership on Organizational Ambidexterity: A Field Study on the Jordanian Chemical Manufacturing Companies. International Journal of Business and Management, 11(5). http://dx.doi.org/10.5539/ijbm.v11n5p328

Aketch, J. R., Odera, O., Chepkuto, P., \& Okaka, O. (2012). Effects of Quality of Work Life on Job Performance: Theoretical Perspectives and Literature Review. Current Research Journal of Social Sciences, 4(5), 383-388.

Aksu, A. A., \& Ozdemir, B. (2005). Individual learning and organization culture in learning organizations: five star hotels in Antalya region of Turkey. Managerial Auditing Journal, 20(4), 422-41. https://doi.org/10.1108/02686900510592098

AL-Abri, R. K., \& AL-Hashmi, I. S. (2007). The Learning Organization and Health Care Education. Sultan Qaboos University Medical Journal, 7(3).

Al-Qatamin, A. A., \& Batayneh, A. M. (2015). A Study of the Nature of Adaptation to Learning Organization Dimensions: The Case of Jordanian Industrial sector. Society of Interdisciplinary Business Research, 4(2).

Anand, A. (2014). Quality of Work Life Evaluation among Service Sector Employees. IOSR Journal of Business and Management, 16(9), 1-12.

Bhatnagar, T., \& Soni, H. (2015). Impact of Quality of work life on Job satisfaction of School Teachers in Udaipur city. IOSR Journal of Business and Management, 10(3), 10-14.

Bordeianu, O., Hapenciuc, C. V., Bejinaru, R., \& Burciu, A. (2014). Dimensions of the learning organization within pharmaceutical companies in romaine. Proceedings of the 8th International management conference, "management challenges for sustainable development ", November 6 th $-7^{\text {th }}$.

Carter, S. M., \& Greer, C. R. (2013). Strategic leadership: Values, styles, and organizational performance. $\begin{array}{lllll}\text { Journal of Leadership \& Organizational Studies, } & \text { 20(4), 375-393. }\end{array}$ https://doi.org/10.1177/1548051812471724

Curado, C. (2006). Organizational Learning and Organizational Design. The Learning Organization, 13(1), 25-48.

Dawoood, S., Mammona, F., \& Ahmed, A. (2015). Learning organization-Conceptual and Theoretical Overview. International Journal of Humanities Social Sciences and Education, 2(4), 93-98.

Farrukh, M., \& Waheed, A. (2015). Learning organization and competitive advantage - an integrated approach. Asian Economic and Social Society, 5(4).

Fatehi, B., Amini, I., Karimi, A., \& Azizi, B. (2015). Impact of Quality of Work Life on Job Satisfaction, Case Study: Sport Teachers in Department of Education from Urmia. Research Journal of Sport Sciences, 3(1). 
Ganguly, R. (2010).Quality of work life and job satisfaction of a group of university employees. Asian Journal of Management Research, 209-216.

Garg, C. P., Munjal, N., Bansal, P., \& Singhal, A. K. (2012). Quality of work life: An overview. International Journal of Physical and Social Sciences, 2(3).

Goh, S. C. (1998). Toward a learning organization: The strategic building blocks. SAM Advanced Management Journal, 63, 15-22.

Hassan, Y., Kashif-ud-din, M., Zark, A., Khalil, M., Abdul, A. W., \& Nasir, A. B. (2011). Job Satisfaction in Private Banking Sector of Pakistan. Global Journal of Management and Business Research, 11(12).

Islam, M. B. (2012). Factors Affecting Quality of Work Life: An Analysis on employees of private limited companies in Bangladesh. Global Journal of Management and Business Research, 12(18).

Janmohammadi, B., Shahmandi, E., Khooravesh, M., \& Ghanizadeh, P. A. (2015). Study of the dimensions of quality of work life and organizational productivity of the staff of taxes organization of Alborz province. Indian Journal of Fundamental and Applied Life Sciences, 5.

Kanten, P., Kanten, S., \& Gurlek, M. (2015). The Effects of Organizational Structures and Learning Organization on Job Embeddedness and Individual Adaptive Performance. Procedia Economics and Finance, 23, 1358-1366. https://doi.org/10.1016/s2212-5671(15)00523-7

Kapinos, K. A., Patrick, F., Greer, N., \& Rutks, I. (2012). The Effect of Working Conditions on Patient Care: A Systematic Review, Evidence-based Synthesis Program.

Leufven, M., Vitrakoti, R., Bergstrom, A., \& Malqvist, M. (2015). Dimensions of Learning Organizations Questionnaire (DLOQ) in a low-resource health care setting in Nepal. Health Research Policy and Systems, 13(6).

Lin, H., \& McDonough III, E. F. (2011). Investigating the role of leadership and organizational culture in fostering innovation ambidexterity. IEEE Transactions on Engineering Management, 58, 497-509. https://doi.org/10.1109/tem.2010.2092781

Linguli, L. M. (2013). Influence of work environment on employees quality of work life and commitment at devki steel mills limitedruiru, a researcher project submitted in partial fulfillment of the requirement for the award of the degree of master of business administration (MBA), school of business, and university of Nairobi, unpublished.

Marsick, V. J., \& Watkins, K. E. (2003). Demonstrating the value of an organization's learning culture: The Dimensions of Learning Organizations Questionnaire. Advances in Developing Human Resources, 5, 132-151. https://doi.org/10.1177/1523422303005002002

Mathis, L., \& Jackson, H. (2003). Human resources management (10th ed.). Thomson publisher, Mason, South Western, USA.

Mbui, S. W. (2014). Relationship between quality of work life and employee commitment among unionized employees in kenya commercial bank (KCB), A research project submitted in partial fulfillment of the requirement for in partial fulfillment of the requirement for the award of the degree of master of business administration (MBA), unpublished.

Mejbel, A. A., Almsafir, M. K., Siron, R., \& Alnaser, A. S. M. (2013). The Drivers of Quality of Working Life (QWL): A Critical Review. Australian Journal of Basic and Applied Sciences, 7(10).

Muindi, F., \& K'Obonyo, P. (2015). Quality of work life, personality, job Satisfaction, competence, and job performance: A critical review of literature. European Scientific Journal, 11(26).

Muthuviknesh, R., \& Kumar, K. A. (2014). The Effect of Occupational Health and Safety Management on Work Environment: A Prospective Study. International Journal of Advance Research in Computer Science and Management Studies, 2(6).

Nanjundeswaraswamy, T. S., \& Swamy. (2012). A literature review on quality of work life and leadership styles. International Journal of Engineering Research and Applications, 2(3).

Nazari, K., \& Pihie, Z. A. L. (2012). Assessing Learning Organization Dimensions and Demographic Factors in Technical and Vocational Colleges in Iran. International Journal of Business and Social Science, 3(3). 
Salem, S. M. W., \& Abu Jarad, O. M. N. (2015). Impact of Quality of the Work Life on Job Involvement in the Institutions of the Palestinian Public Sector. American Journal of Business And Management, 4(3). https://doi.org/10.11634/216796061504696

Sekaran, U. (2008). Research Methods for Business: A Skill Building Approach. New York: John Wiley And Sons.

Senge, P. M. (1990). The Fifth Discipline: The art and practice of the learning organization. New York, NY: Doubleday. https://doi.org/10.1002/hrm.3930290308

Sinha, C. (2012). Factors affecting quality of work life: Empirical Evidence from Indian Organizations, Australian Journal of Business and Management Research, 1(11), 31-40.

Soni, H., \& Rawal, Y. S. (2014). Impact of Quality of Work Life on Employee Satisfaction in Hotel Industry. IOSR Journal of Business and Management, 16(3). https://doi.org/10.9790/487x-16343744

Varghese, S., \& Jayan, C. (2013). Quality of Work Life: A Dynamic Multidimensional Construct at Work Place Part II. Guru Journal of Behavioral and Social Science, 1(2), 91-104.

Vemic, J. (2006). Employees training and development and the learning organization. Economics and Organization, 4(2).

Walton, R. E. (1974). Improving the quality of work life. Harvard Business Review.

Wang, Y. L., \& Ellinger, A. D. (2008). Organizational Learning and Innovation Performance: A Review of the Literature and the Development of a Conceptual Framework and Research Hypotheses. Academy of Human Resource Development International Research Conference in the Americas.

Wang, P. Y. (2006). Human Resource Management Plays a New Role in Learning Organizations. The Journal of Human Resource and Adult Learning, 52-56.

Watkins \& Marsick. (2004). The Construct of the Learning Organization: Dimensions, Measurement and Validation. Human Resource Development Quarterly, 15(1). https://doi.org/10.1002/hrdq.1086

\section{Copyrights}

Copyright for this article is retained by the author(s), with first publication rights granted to the journal.

This is an open-access article distributed under the terms and conditions of the Creative Commons Attribution license (http://creativecommons.org/licenses/by/4.0/). 